each appoints a full time manager to look after the commercial activities. Once the centres are operating successfully, it is expected that they will be self supporting, and the money will be freed to start new centres at other universities.

The first centres reflect the British Government's interest in tribology-the study of interacting surfaces in relative motion, including friction, wear and bearing design. The universities of Leeds and Swansea and the establishment at Risley will be concerned with tribology. The University of Strathclyde has a general brief covering the whole of engineering; Cranfield will look after precision engineering and Bangor will be responsible for instrumentation and control engineering. Each unit will be undertaking contract research for industry and the project is intended to be a thoroughly commercial one. But the ministry foresees no conflict between the units and the universities proper, and the minister himself goes near to saying that the commercial pressures will be a good thing for all concerned. "The universities are going to sell themselves to industry," Mr Benn declares.

In approving the centre at Risley, the minister seems implicitly to have rejected the recommendation of the Select Committee on Science and Technology, which reported last week. The committee said that the authority should not undertake work on subjects not inextricably linked with its primary task. Mr Benn said that the policy of diversification is "well established".

The emphasis on tribology, and the name, derive from a working party set up by Lord Bowden when he was Minister of State at the Department of Education and Science in 1964. The committee, under the chairmanship of $\mathrm{Mr} \mathrm{H}$. Peter Jost, was the originator of the now celebrated claim that industry could save $£ 500$ million a year by the better use of lubrication. In support of these figures, Mr Jost has quoted the experience of East Germany, where training in lubrication has been made compulsory, and qualified lubrication engineers have been appointed to state owned works. Within a few years, Mr Jost said, the East German steel industry has saved $£ 2-£ 3$ million, which would have meant $£ 21$ million in Britain. One of the conclusions of the Jost report was that inadequate training in tribology would be a major stumbling block-but Mr Benn's new proposals make no direct provision for this.

\section{Glass Reinforced Plastics}

A HAPPY accident in 1940, when catalysed polyester resin was spilt over several layers of glass fibre, produced the first glass reinforced plastic (GRP). Since then the highly satisfactory structural properties of this material have been studied and it can now be considered alongside the more conventional building materials of concrete and steel. The development, properties and design qualities of glass reinforced polyester resins were described by $\mathrm{Mr}$ Brian J. Bell at a meeting of the Society of Engineers on December 4.

Polyester resin has the great advantage of polymerizing at room temperature and low pressure. GRP can therefore be moulded (layed-up) by hand, and can be used for moulds of any size and shape. It is resistant to weather and many chemicals. These advantages are somewhat offset by the slowness of production compared with injection moulding methods, and skill is required to produce a material of consistent strength. Glass fibre for reinforcement and the resin itself are expensive, but no costly equipment is required for production of GRP. Fillers can be added which alter the gelation time, and mechanical, thixotropic and self-extinguishing properties of GRP and the form of reinforcement can also be chosen to suit the required design properties. The most common form of reinforcement is the chopped strand mat in which 2 in. random strands are bonded together with resin to form a mat which weighs from 1 to $2 \mathrm{oz}$. per square foot.

GRP can be produced by contact pressure and by low or high pressure moulding. Each method has variations which are introduced to suit the size, shape, dimensional tolerance, cost, strength and quantity of the required product. In all cases a release agent is required for releasing the product from the mould. $\mathrm{Mr}$ Bell gave examples of the general properties of various laminates that can be made from GRP, and compared its properties with those of mild steel. Volume by volume GRP can be almost twice as strong as mild steel, while weight for weight it can be thirteen times stronger. But sometimes it lacks rigidity, and variations can occur in mechanical properties because of differences in manufacturing conditions or in composition. Mr Bell described ways in which the limited span of GRP can be extended, particularly by folding the material-despite the unsolved problem of prestressing, GRP obviously has a great future.

\section{Another Food Supplement}

LAST week the American University of Beirut announced that a high protein food supplement, called "l'aubina", had been developed in Beirut under the direction of the Columbia University Institute of Nutrition Sciences and financed by the United States National Institutes of Health. It is the latest addition to the growing list of food supplements developed from local products in various parts of the world in an attempt to combat local malnutrition with locally grown produce. "L'aubina" is made from chick peas and parboiled wheat-both are grown in the Middle East, North Africa, India and Pakistan-with small amounts of bone ash and skim milk. It is easy to make-apparently any food manufacturer could make it with existing machinery - and cheap. In tests, the nutritional health of children was maintained by a daily supplement of 7 ounces of "l'aubina" which would cost only about 2s. 1d. (25 cents) to produce. It contains $17 \cdot 1$ per cent protein-about the same amount as roast leg of lamb-adequate amounts of vitamins $A$ and $D$ and some vitamin $B$ and calcium.

The question now is whether a commercial producer can be found to produce "l'aubina" in bulk and, even more important, whether it will be accepted by those who are suffering from malnutrition. Past experiences are not at all encouraging. In Peru, a supplement called "Peruvita", which is made from the local plant quinoa, was developed over a period of five years but abandoned last year because it was not accepted. Similarly in Guatemala, "Incaparina". made from cotton seed and sorghum, has not been accepted. It is still produced but only reaches 2 per cent of the children in the country. So great is the prejudice against these supplements that even 